\title{
Intra-Operative \& Post-Operative Complications in Pediatric Anesthesia: A Study in Cumilla Medical College, Cumilla, Bangladesh
}

\author{
Md. Delwar Hossain ${ }^{1 *}$, Md. Atower Rahman², Md. Kamrul Hossain ${ }^{3}$, Mohammad Shakhawat Hossain ${ }^{4}$
}

${ }^{1}$ Assistant professor, Dept. of Anaesthesiology \& ICU, Cumilla Medical College, Cumilla, Bangladesh

${ }^{2}$ Associated professor, Dept. of Anaesthesiology \& ICU, Cumilla Medical College, Cumilla, Bangladesh

${ }^{3}$ Assistant Professor, Departmnt of Anaesthesiology \& ICU, Cumilla Medical College, Cumilla, Bangladesh

${ }^{4}$ Assistant professor, Dept. of Anaesthesiology, Cumilla Medical College, Cumilla, Bangladesh

DOI: $10.36347 /$ sjams.2020.v08i09.030

| Received: 03.09.2020 | Accepted: 13.09.2020 | Published: 20.09.2020

*Corresponding author: Md. Delwar Hossain

Abstract

Original Research Article

Introduction: Pediatric patients differ in their drug requirements because of their smaller body size, differences in body composition and handling capacity of drugs. Usually dosages are based on body weight, because it correlates so intimately with body water compartments. Objective: To find out the Intra-Operative \& Post-Operative Complications in Pediatric Anesthesia. Materials \& Methods: The present study was conducted in the Department of Anaesthesiology \& ICU, Cumilla Medical College, Cumilla, Bangladesh during from January 2017 to December 2017. It included 250 pediatric patients of both gender. Parents were informed regarding the study and written consent was obtained. Ethical clearance was taken from institutional ethical committee. General information such as name, age, sex, ASA status, technique of anesthesia and complications were recorded. Results: The present study was conducted to identify anesthesia-related complications in pediatric patients. The present study was conducted on 250 pediatric patients of both genders. Factors such as conscious state, colour, respiration, pulse and blood pressure were also assessed. Age group 1 month- 1 year had 22 males and 33 females. 1-5 years had 45 males and 50 females, 5-10 years had 15 males and 20 females and 10-14 years had 40 males and 25 females. The difference was non- significant (P-0.5). Patients had ASA I (180), ASA 2 (50), ASA 3 (15), ASA 4 (3) and ASA 5 (2) status. The difference was significant (P-0.05). Type of anesthesia was general anesthesia (200), general anesthesia with caudal block (27), subarachnoid block (5) and general anesthesia with local anesthesia (18). The difference was significant (P-0.01). Common intra- operative complications were bradycardia (5), tachycardia (4), hypotension (4), hypertension (3), cardiac arrest (2), brochospasm (1), hypoventilation (2), pain (3) and prolonged unconsciousness (1). The difference was significant (P-0.01). Post- operative complications were shivering (6), pain (5), hemorrhage (7), hypoventilation (3), respiratory arrest (2), laryngospasm (4) and hypoventilation (2). The difference was non- significant (P-0.5). Conclusion: In order to avoid or minimize these complications occurring at induction to the barest minimum, a consultant anesthetist or an experienced anesthetist must always be in attendance to handle difficult cases.

Keywords: General Anesthesia, Laryngospasm, Pediatric.

Copyright @ 2020: This is an open-access article distributed under the terms of the Creative Commons Attribution license which permits unrestricted use, distribution, and reproduction in any medium for non-commercial use (NonCommercial, or CC-BY-NC) provided the original author and source are credited.

\section{INTRODUCTION}

Typical complications in pediatric anesthesia are respiratory problems, medication errors, difficulties with the intravenous puncture and pulmonal aspiration. In the postoperative setting, nausea and vomiting, pain, and emergence delirium can be mentioned as typical complications. Major differences in anatomy and physiology in the small infant have important consequences in many aspects of anesthesia. The physical disparity between the adult and child diminishes at 10-12 years of age although major psychological differences continue till adolescence. In order to reduce the morbidity and mortality associated with pediatric anesthesia, the anesthetist should have a sound knowledge of the physiologic, anatomic and pharmacologic peculiarities of each developmental stage of childhood. Laryngospasm is a common occurrence in pediatric anesthesia and is usually easy to manage. It is however a significant cause of severe adverse outcome including cardiac arrest and its sequelae [1]. Pediatric patients differ in their drug requirements because of their smaller body size, differences in body composition and handling capacity of drugs. Usually dosages are based on body weight, because it correlates so intimately with body water compartments. Pediatric anesthesia morbidity and mortality in the perioperative period has been studied 
by Cohen et al., [2], an incidence of $35 \%$ was reported by the same author. In another multicenter study, complications related to anesthesia in infants and children were also reported. A study carried out in Nigeria revealed an incidence of $10 \%$ adverse events in pediatric surgical emergencies. Advances in monitoring and the declining use of halothane have led to a change in the types of risk. Risk is defined as the chance or possibility of danger, loss or injury. It is therefore an ever-present part of life. What constitutes a serious or worrying risk is dependent upon perspective. This is readily illustrated in the health care industry. Risk is viewed in quite different lights by patients, doctors, hospital managers, insurance companies and policymakers. While patients worry about the prospect of failed treatment and unpleasant side effects, anesthetists will be more concerned about the immediate risks of major disability and death associated with surgery. Similarly, while individual hospital managers and insurance companies are keen to minimize their exposure to financial liability, health policy-makers aim to ensure patients' access to the most appropriate centers for their treatment [3]. The present study was conducted to identify anesthesia-related complications in pediatric patients.

\section{Materials \& METHODS}

The present study was conducted in the Department of Anaesthesiology \& ICU, Cumilla Medical College, Cumilla, Bangladesh during from January 2017 to December 2017. It included 250 pediatric patients of both gender. Parents were informed regarding the study and written consent was obtained. Ethical clearance was taken from institutional ethical committee. General information such as name, age, sex, ASA status, technique of anesthesia and complications were recorded. Factors such as conscious state, colour, respiration, pulse and blood pressure were also assessed. Results were subjected to statistical analysis using chi- square test. $\mathrm{P}$ value $<0.05$ was considered significant. All data analysis windows "SPSS" version 19.0.

\section{RESUlTS}

The present study was conducted on 250 pediatric patients of both genders. General information such as name, age, sex, ASA status, technique of anesthesia, and complications were recorded. Factors such as conscious state, colour, respiration, pulse and blood pressure were also assessed. Age group 1 month1 year had 22 males and 33 females. 1-5 years had 45 males and 50 females, 5-10 years had 15 males and 20 females and 10-14 years had 40 males and 25 females. The difference was non- significant (P-0.5) (Table-1).

Table-1: Age distribution of patients $(\mathrm{N}=250)$

\begin{tabular}{|l|l|l|l|}
\hline Age & Males & Females & P value \\
\hline 1 month-12 month & 22 & 33 & \multirow{2}{*}{0.5} \\
\cline { 1 - 3 } 1-5 years & 45 & 50 & \\
\cline { 2 - 3 } 5-10 years 15 20 & 15 & 20 & \\
\hline 10-14 years 40 25 & 40 & 25 & \\
\hline Total & 122 & 128 & \\
\hline
\end{tabular}

Figure-1 shows that patients had ASA I (180), ASA 2 (50), ASA 3 (15), ASA 4 (3) and ASA 5 (2) status. The difference was significant (P-0.05).

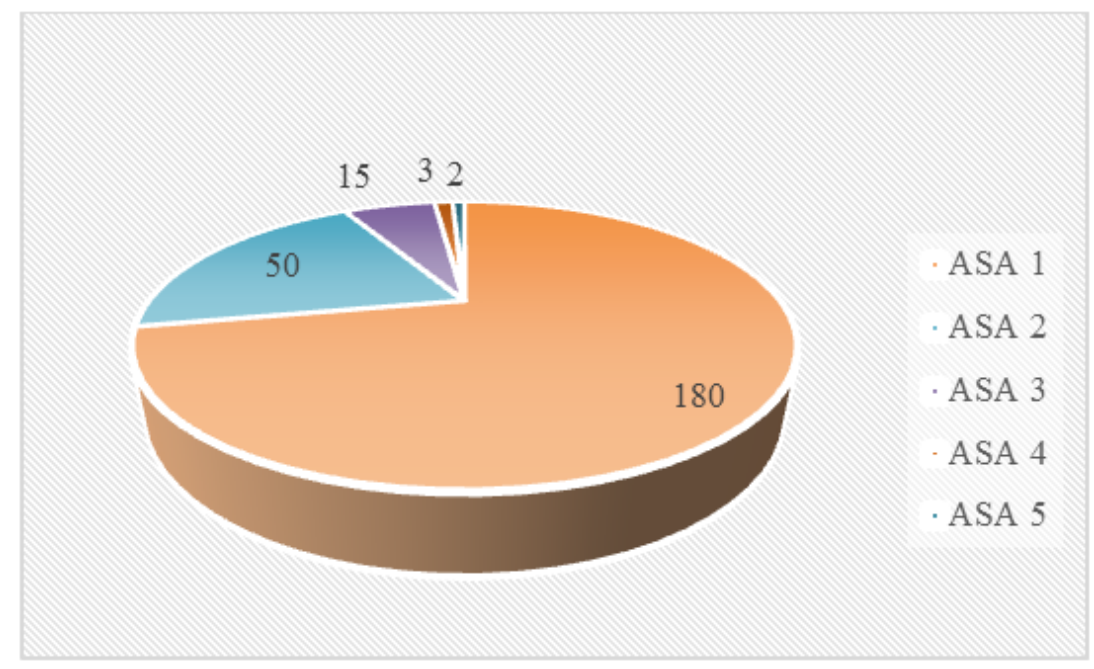

Fig-1: ASA status in patients was significant $(\mathbf{P}-\mathbf{0 . 0 5})$ 
Figure-2 shows that type of anesthesia was general anesthesia (200), general anesthesia with caudal block (27), subarachnoid block (5) and general anesthesia with local anesthesia (18). The difference was significant (P-0.01).

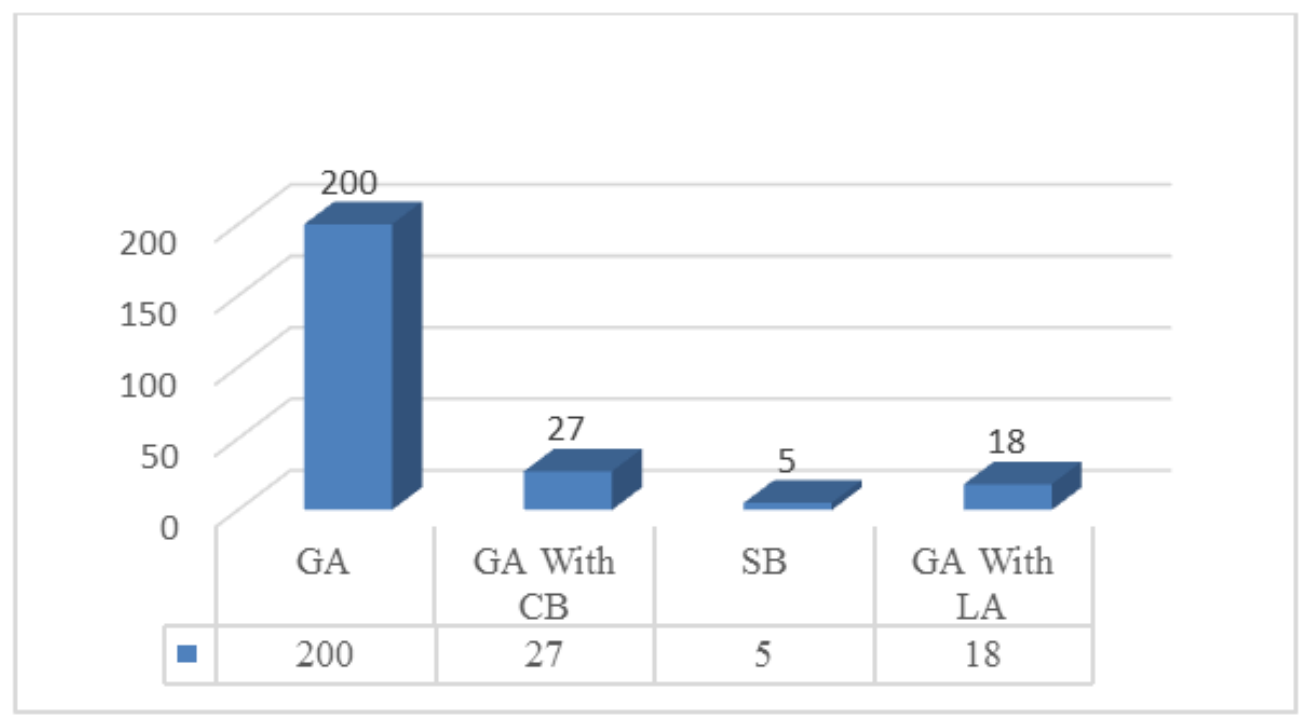

Fig-2: Choice of Anesthesia

Figure-3 shows that common intra- operative complications were bradycardia (5), tachycardia (4), hypotension (4), hypertension (3), cardiac arrest (2), brochospasm (1), hypoventilation (2), pain (3) and prolonged unconsciousness (1). The difference was significant (P-0.01).

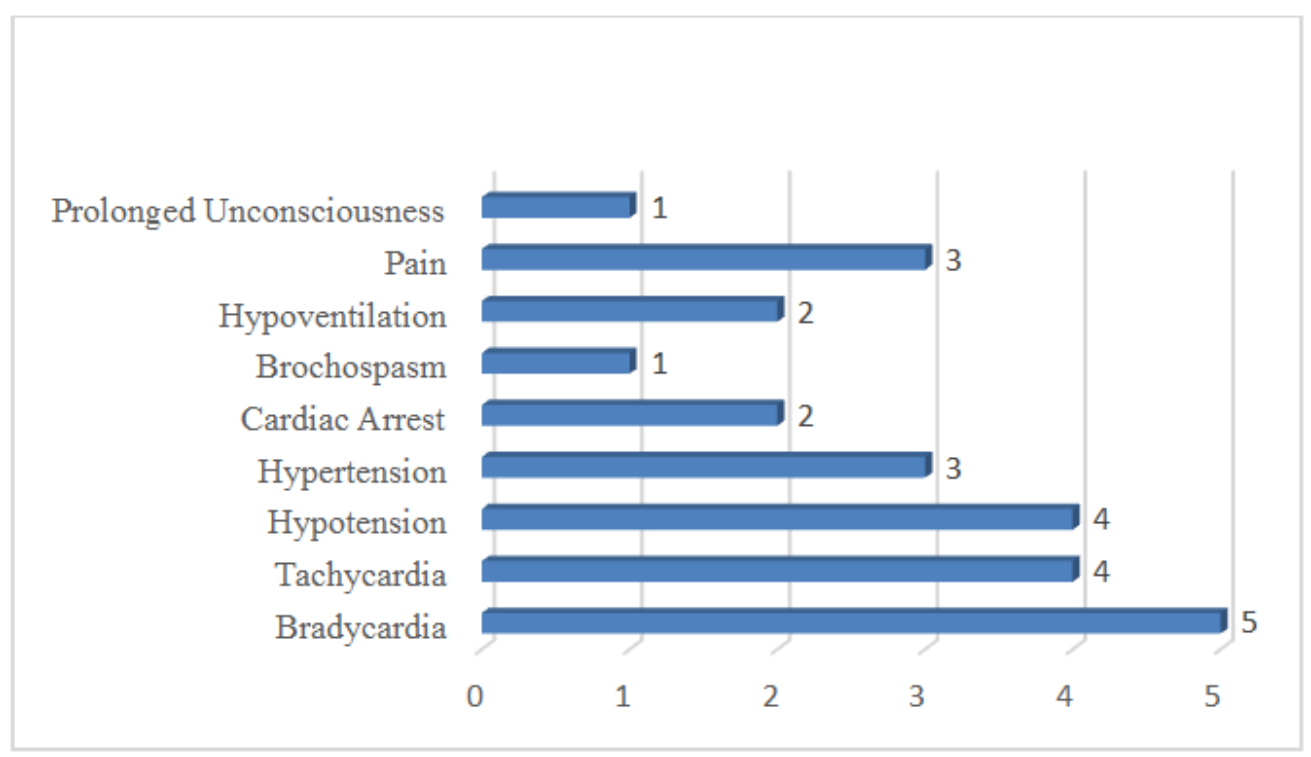

Fig-3: Intra-operative complications

Figure-4 shows that post- operative complications were shivering (6), pain (5), hemorrhage (7), hypoventilation (3), respiratory arrest (2), laryngospasm (4) and hypoventilation (2). The difference was non- significant (P-0.1). 


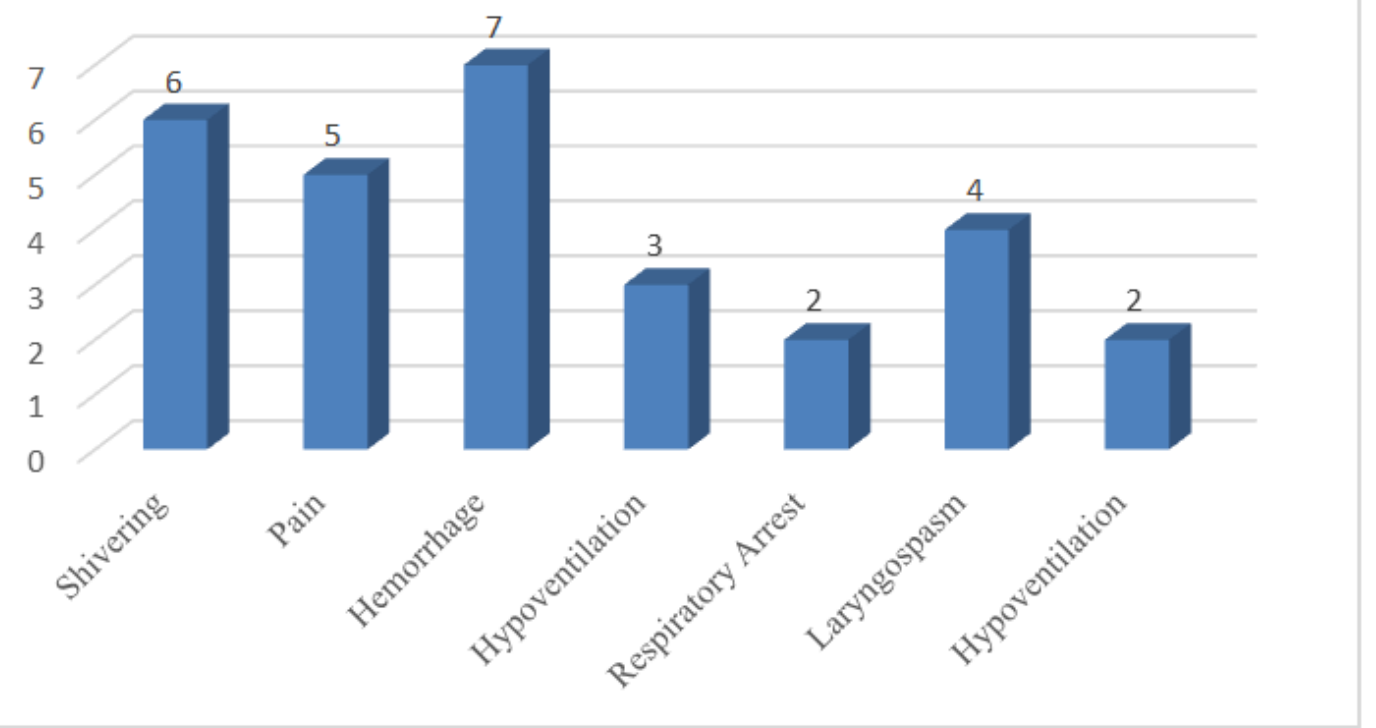

Fig-4: Post-operative complications

\section{DiscUSSION}

Standard monitoring is essential in pediatric anesthesia care particularly for early detection and prevention of dangerous complications such as bradycardia, hypotension, hypoxia and adverse temperature changes. The hallmark of pediatric anesthesia has always been the precordial stethoscope because it allows constant monitoring of breath sounds, along with the heart sounds, rate and rhythm. Changes in clinical status happen quickly in the newborn with only subtle signs heralding serious alterations in the patient's clinical status [4]. Difficulty of intravenous cannulation is sometimes encountered especially in the preterm neonates, overweight babies and when most peripheral veins had been ruined from withdrawal of blood sample for laboratory investigations and intravenous therapy. This problem was sometimes solved with the help of pediatricians or rarely the surgeons who perform venous cut downs [5]. The present study was conducted to identify anesthesiarelated complications in pediatric patients. In this study, maximum patients were in age group 1-5 years followed by 10-14 years, 1month- 1 year and 5-10 years. The type of anesthesia was general anesthesia, general anesthesia with caudal block, subarachnoid block and general anesthesia with local anesthesia. This is similar to Morray [6]. Complications arising at induction of anesthesia in neonates and small infants in our study were mainly respiratory and cardiovascular. They may manifest as apnea, bronchospasm, laryngospasm, cyanosis, bradycardia and cardiac arrest. These are likely to be due to stimulation of the larynx during laryngoscopy and tracheal intubation at light planes of anesthesia. Neonates and infants have very active airway reflexes and therefore require adequate depth of anesthesia for laryngoscopy and tracheal intubation. The preterms infants are more prone to developing postoperative respiratory complications as evidenced by our study. In neonates, if bradycardia is not promptly treated with $100 \%$ oxygen, they readily develop hypoxic cardiac arrest [7]. We found that common intra-operative complications were bradycardia, tachycardia, hypotension, hypertension, cardiac arrest, brochospasm, hypoventilation, pain and prolonged unconsciousness. Post-operative complications were shivering, pain, hemorrhage, hypoventilation, respiratory arrest, laryngospasm and hypoventilation. This is in agreement with Jiminez $\mathrm{N}$ [8]. It has been recognized that infants and children require adequate pain management and if not received May actually adversely affect patient outcome. Ageappropriate pain assessment is essential and both subjective and objective assessment tools may be utilized depending on patient age and clinical status. Many pain assessment scales have been develop to assess pain in children. The most reliable form of pain assessment is self-report. Infants less than 1 month old have the highest rate of adverse events both intraoperatively and in the recovery room [9]. Anesthesia, because of its depression on metabolism and dilatation of cutaneous vessels, tends to cause a progressive fall in body temperature $[10,11]$. In the recovery room, pain was treated with opioid analgesics after excluding other causes of crying and discomfort. Our study showed a similar finding. The presence of pain implies inadequate analgesia following surgery. There have been a number of myths and misunderstandings related to pain in children which has led to historically inadequate treatment of pediatric pain [12]. 


\section{CONCLUSION}

In order to avoid or minimize these complications occurring at induction to the barest minimum, a consultant anesthetist or an experienced anesthetist must always be in attendance to handle difficult cases.

\section{REFERENCES}

1. Murat I, Constant I, Maud'huy H. Perioperative anaesthetic morbidity in children: a database of 24 165 anaesthetics over a 30-month period. Ped Anes. 2004; 14: 158-166.

2. Tiret L, Nivoche Y, Hatton F, Desmonts JM, Vourc'h G. Complications related to anaesthesia in infants and children: a prospective survey of 40240 anaesthetics. BJA: British Journal of Anaesthesia. 1988 Sep 1; 61(3):263-9.

3. Cohen MM, Cameron CB, Duncan PG. Pediatric anesthesia morbidity and mortality in the perioperative period. Anesthesia \& Analgesia. 1990 Feb 1; 70(2):160-7.

4. Tay CL, Tan GM, Ng SB. Critical incidents in paediatric anaesthesia: an audit of $10 \quad 000$ anaesthetics in Singapore. Pediatric Anesthesia. 2001 Nov 9; 11(6):711-8.

5. Flick RP, Sprung J, Harrison TE, Gleich SJ, Schroeder DR, Hanson AC, Buenvenida SL, Warner DO. Perioperative Cardiac Arrests in Children between 1988 and 2005 at a Tertiary Referral CenterA Study of 92,881 Patients. The
Journal of the American Society of Anesthesiologists. 2007 Feb 1; 106(2):226-37.

6. Gi WM, Cheney FW. A comparison of pediatric and adult anesthesia closed malpractice claims. Anesthesiology. 1993 Mar; 78(3):461-7.

7. Gobbo Braz L, Braz JR, MÓdolo NS, Nascimento P, Brushi BA, Raquel De Carvalho L. Perioperative cardiac arrest and its mortality in children. A 9- year survey in a Brazilian tertiary teaching hospital. Pediatric Anesthesia. 2006 Aug $1 ; 16(8): 860-6$.

8. Jimenez N, Posner KL, Cheney FW, Caplan RA, Lee LA, Domino KB. An update on pediatric anesthesia liability: a closed claims analysis. Anesthesia \& Analgesia. 2007 Jan 1; 104(1):14753.

9. Coté CJ, Rolf N, Liu LM, Goudsouzian NG, Ryan JF, Zaslavsky A, Gore R, Todres TD, Vassallo S, Polaner D. A single-blind study of combined pulse oximetry and capnography in children. Anesthesiology. 1991 Jun; 74(6):980-7.

10. Feldman S. Neurological disease in relation to Anaesthesia - A Practice of Anaesthesia 4th Edition 937; 1978.

11. Roe CF. Temperature Regulation in Anaesthesia. Physiological and Behavioural Temperature regulation. 1970 .

12. Cote CJ. Paediatric Anaesthesia: In Anesthesia Miller R.D. 1990, Churchill Livingstone. 3rd Edition, 2: 1897-1926. 